\title{
O EIXO ANÁLISE LINGUÍSTICA NA BNCC: UMA ANÁLISE DAS LINHAS DE CONTINUIDADE ENTRE AS DIFERENTES VERSÕES DA BASE
}

\author{
Jéssica Rodrigues Silva* \\ Denise Lino de Araújo*
}

RESUMO: Este estudo investiga como o eixo Análise Linguística (AL) foi (re)construído na Base Nacional Comum Curricular (BNCC) do Ensino Fundamental. Mais especificamente, destaca as linhas de continuidade que este eixo apresenta entre a segunda versão (BRASIL, 2016) e a terceira versão homologada (BRASIL, 2017) Essa pesquisa tem respaldo teórico-metodológico na Linguística Aplicada, de natureza qualitativa e documental, com enfoque interpretativo no eixo AL do componente de Língua Portuguesa. Dentre aporte teórico, podemos destacar alguns estudos, como os Bezerra e Reinaldo (2013), Franchi ([1987] 2006), Geraldi ([1984] 1997), Mendonça (2006) sobre a prática de Análise Linguística no contexto escolar. Os dados analisados apontaram que na parte discursiva do documento as linhas de continuidade entre as versões da BNCC investigadas mostram-se em continuidade textual - manifesta por mecanismos de reiteração e paráfrase -, epistemológica - manifesta na manutenção de ideias e conceitos -, e por filiação documental - manifesta na vinculação a documentos curriculares anteriores.

PALAVRAS-CHAVE: Análise linguística; BNCC; Ensino fundamental; Língua portuguesa; Linguística aplicada.

\section{Considerações iniciais}

A Base Nacional Comum Curricular (BNCC) é o atual documento normatizador de ensino da Educação Básica do país. Este é um documento regulador que tem como proposta nortear tanto os currículos dos sistemas e redes de ensino das Unidades Federativas quanto às propostas pedagógicas de todas as escolas públicas e privadas do Brasil (Brasil, 2017). Em seu processo de construção, de acordo com o Ministério da Educação (MEC),

\footnotetext{
${ }^{*}$ Mestranda em Linguagem e Ensino pela Universidade Federal de Campina Grande (UFCG).

** Doutora em Educação plena Universidade de São Paulo (Usp). Professora associada da Unidade Acadêmica de Letras da Universidade Federal de Campina Grande (UFCG), onde atua como docente na graduação em Letras e no Programa de Pós-graduação em Linguagem e Ensino.
} 
a BNCC passou por três diferentes versões até chegar a versão homologada para todas as etapas da Educação Básica, em 14 de dezembro de $2018^{1}$.

A Base é um dos componentes das políticas públicas que regem o Sistema Nacional de Educação e se insere num amplo processo de reformulação das políticas educacionais nacionais. Formulada em um contexto político marcado por uma rotatividade administrativa conturbada, o seu processo de elaboração perpassa três diferentes governos federais, e está sendo implementada em um outro bem diferente dos anteriores. As diferentes versões deste documento, ao mesmo tempo que se inseriam na cadeia da discussão e aparentemente resultavam do processo, eram também produto de uma nova concepção e de uma nova gestão, junto ao MEC ou frente ao próprio Brasil.

O foco deste estudo é a BNCC do Ensino Fundamental (EF), especialmente a segunda versão, publicada em 3 de maio de 2016, e a última versão homologada do documento ( $3^{a}$ versão) homologada em 20 de dezembro de 2017 que guardam muitas semelhanças quanto à arquitetura estrutural e conceitual. Na versão homologada, a BNCC do EF está organizada por áreas de conhecimento, depois por competências de área, componentes curriculares e suas competências específicas, que, por sua vez, são direcionadas para os anos Iniciais e Finais do Ensino Fundamental. $\mathrm{Na}$ área de Linguagem dos Anos Finais, mais especificamente no componente de Língua Portuguesa, a BNCC assume uma perspectiva enunciativo-discursiva da linguagem, em que salienta o texto como unidade de trabalho, conforme destacado a seguir.

Tal proposta assume a centralidade do texto como unidade de trabalho e as perspectivas enunciativo-discursivas na abordagem, de forma a sempre relacionar os textos a seus contextos de produção e o desenvolvimento de habilidades ao uso significativo da linguagem em atividades de leitura, escuta e produção de textos em várias mídias e semioses. (BRASIL, 2017, 67)

\footnotetext{
${ }^{1}$ As pesquisas desenvolvidas por nosso grupo de estudo apontam a existência de quatro versões, dado que versão homologada não é mesmo texto que circulava em todo o Brasil até Novembro de 2017. Mas para efeito didático, neste artigo, a versão homologada será indicada como a $3^{\mathrm{a}}$ versão, tal como divulgado no discurso oficial.
} 
Além do texto como unidade a partir da qual todo o trabalho deve ser realizado, o componente Língua Portuguesa encontra-se organizado em torno de quatro eixos: Leitura, Produção de Textos, Oralidade e Análise Linguística/Semiótica. Esses eixos organizadores, por sua vez, estão relacionados a cinco campos de atuação elencados pela base: Campo Jornalístico/midiático; Campo de Atuação na vida pública; Campo das Práticas de estudo e pesquisa e Campo Artístico-literário. A BNCC elenca ainda Objetos de Conhecimento e Habilidades a serem asseguradas aos alunos nos diferentes contextos escolares.

A arquitetura estrutural da BNCC enquanto documento possui dois grandes segmentos: o texto expositivo e as tabelas com indicação de campos, eixos, objetos e habilidades. O segmento textual dos documentos compreende as descrições das competências gerais e específicas de cada área de conhecimento e por componente curricular e os fundamentos teóricos do componente. As tabelas, além da indicação acima mencionadas, estão organizadas por ciclos e séries. Essa organização em campos e eixos é específica do componente Língua Portuguesa, os demais componentes apresentam unidades temáticas, ao lado dos objetos de conhecimento e habilidades.

Pretende-se neste artigo, investigar como o eixo Análise Linguística foi (re)construído nas diferentes versões da BNCC do EF. Mais especificamente, destacar as linhas de continuidade que este eixo apresenta entre a segunda versão (BRASIL, 2016) e a versão homologada (BRASIL, 2017). Essa pesquisa tem respaldo teórico-metodológico na Linguística Aplicada, a metodologia de pesquisa usada é de natureza qualitativa e documental, com enfoque interpretativo no eixo AL do componente de Língua Portuguesa.

Este artigo está organizado em quatro partes. A primeira parte, esta introdução, intitulada "Considerações iniciais". Segue-se uma seção sobre os estudos teóricos de AL, intitulada "A Análise Linguística no contexto escolar". Na terceira parte, explicitam-se os aspectos metodológicos que nos ajudaram a ler dados, intitulada "Bases e procedimentos para análise de dados". A quarta parte, intitulada "Análise de dados: Linhas de continuidade do eixo análise linguística na BNCC", apresenta outras três subseções de análise de dados, nas quais são indicadas as linhas de continuidade entre a $2^{a}$ e a $3^{a}$ versão da BNCC. E por fim, as considerações finais. 


\section{A Análise Linguística no contexto escolar}

Os estudos linguísticos sobre Análise Linguística no contexto escolar aliada às práticas de leitura e de produção de textos têm José Wanderley Geraldi como precursor do processo de didatização. Este conceito está presente no texto Unidades básicas do ensino de português (1981), publicado mais tarde na coletânea O texto na sala de aula (GERALDI, [1984] 1997). Nesse contexto,

O uso da expressão "Análise Linguística", não se deve ao mero gosto por novas terminologias. A análise linguística inclui tanto o trabalho sobre as questões tradicionais da gramática quanto questões amplas a propósito do texto; adequação do texto aos objetivos pretendidos; análise dos recursos expressivos utilizados (metáforas, metonímias, paráfrases, citações, discursos direto e indireto, etc.); organização e inclusão de informações etc. Essencialmente, a prática de análise linguística não poderá limitar-se à higienização do texto do aluno em seus aspectos gramaticais e ortográficos, limitando-se a "correções". Trata-se de trabalhar com o aluno o seu texto para que ele atinja seus objetivos junto aos leitores a que se destina. (GERALDI, [1984] 1997, p. 74)

A prática de análise linguística baseia-se numa concepção sociointeracionista de linguagem e em práticas que articulam leitura, produção de texto e análise linguística, em prol do desenvolvimento das competências de compreensão e elaboração textual o aluno. O autor ainda deixa claro que "o objetivo não é o aluno dominar a terminologia (embora possa usá-la), mas compreender o fenômeno [linguístico] em estudo" (GERALDI, [1984] 1997, p. 74).

O autor defende que o ensino gramatical somente tem sentido se auxiliar o aluno a refletir sobre o funcionamento da língua. Sua proposta é de uma reorientação de ensino, com base na leitura e escrita de textos como práticas sociais significativas e integradas, e na análise de problemas encontrados na produção textual como mote para a prática de análise linguística, em vez dos exercícios estruturais de gramática (MENDONÇA, 2006).

A proposta de Geraldi ([1984]1997) reorienta o paradigma de ensino de língua materna ao privilegiar os textos produzidos pelos próprios alunos e usar as gramáticas e dicionários como ferramentas para reflexão sobre os efeitos de sentido produzidos nos textos. 
Essa proposição desloca o papel didático-pedagógico das gramáticas normativas de modelo a ser seguido, no ensino gramatical tradicional, para o de ferramenta para construção/reflexão de textos, em busca de ampliação dos conhecimentos linguísticos em pró de práticas de leitura e escrita.

De acordo com Lino de Araújo (2017), o conceito de prática de análise linguística tal qual conhecemos hoje é fruto tanto de trabalhos publicados na década de 80 do século XX, como os de Franchi (1987) que serviram de ponto inicial para reflexão sobre processos de descrição linguística e de ensino de língua materna, quanto do próprio movimento de revisão do conceito feito pelo Geraldi em trabalhos posteriores. Além das contribuições feitas por autores como Mendonça (2006) e Bezerra e Reinaldo (2013), a difusão desse conceito em larga escala feita por documentos parametrizadores de ensino como os Parâmetros Curriculares Nacionais de Língua Portuguesa, $3^{\circ}$ e $4^{\circ}$ Ciclos do Ensino Fundamental (BRASIL, 1998), ajudaram a lapidar o conceito e desenvolver essa metodologia de ensino.

Dentro do percurso historiográfico dos estudos linguísticos, o conceito teórico-metodológico de AL, segundo Lino de Araújo (2017, p. 138), filia-se aos estudos da Linguística Textual, da Semântica Enunciativa e a "toda uma tradição docente baseada na autonomia do professor para construir currículos localmente situados a partir das experiências e necessidades dos alunos". Isto nos remete ao momento em que a produção intelectual sobre o ensino de Português é marcada pela virada linguística e os estudos sobre currículo se filiam às perspectivas críticas, dentre as quais a perspectiva freireana tem grande relevo e nota-se a sua influência na proposta de Geraldi.

A prática pedagógica com base em um currículo situado de ensino de língua materna ainda se encontra em um momento de transição entre práticas de ensino de caráter tradicional e inovador. De acordo com Mendonça (2006), há uma mescla de perspectivas, em que o ensino tradicional de gramática e as novas práticas de ensino convivem juntas, às vezes, até de maneira conflituosa. A autora explica que a AL surge como alternativa complementar às práticas de leitura e produção de texto, uma ferramenta para o desenvolvimento de ha- 
bilidades essenciais dessas práticas sociais, uma vez que, na escola, analisar o uso de determinada palavra no texto só tem sentido se isso trouxer alguma contribuição à compreensão do funcionamento da linguagem, auxiliando a formação ampla do falante.

Pensar o ensino de Português pautado no paradigma de inovação educacional na contemporaneidade está ligado diretamente aos novos desafios que o mundo contemporâneo apresenta à escola. Diante do "novo" e "multi" mundo que se constitui em nossa contemporaneidade de relações multiculturais com multiletramentos, as práticas de linguagem exigem novas reflexões no processo de ensino. No que se refere ao ensino de Língua Portuguesa, diante das inúmeras práticas sociais que se delineiam e do alargamento da noção de letramento por meio da tecnologia, as práticas de linguagens demandam novas reflexões no processo de ensino de língua materna, uma vez que novas são as relações multiculturais entre o que é local e global, valorizado e não valorizado; novas são as formas de circulação dos textos e as situações de produção de discursos; novos são os gêneros e as ferramentas de leitura-escrita (cf. TEIXEIRA, LITRON, 2012).

Apesar de que "quando se trata do que acontece numa sala de aula, não há padrões inflexíveis, modelos fixos; na verdade, recorre-se a diversos caminhos teóricos metodológicos para a condução do processo de ensino-aprendizagem” (MENDONÇA, 2006, p. 200). Em busca desse ensino-aprendizagem inovador, transformador, diversos professores e agentes de políticas linguísticas de mudanças no ensino preconizam que é necessária a colaboração de todos para uma mudança efetiva. Embora não haver relações rígidas entre o que é inovação e o que é tradição, uma vez que essa relação é porosa, permeada por diferentes estratégias metodológicas que tenham o uso da língua como matéria prima principal (APARÍCIO, 2006). Numa perspectiva inovadora de ensino entende-se a importância de oportunizar aos alunos o uso efetivo da língua, agenciar a reflexão epilinguística na aula, seja através de textos autorais ou outros bem escritos e que cumprem determinados papéis sociais, e, só depois disso, ensinar a metalinguagem.

Dessa maneira, em se tratando do ensino de língua, entendemos inovação não como algo binário, mas como desestabilizador, que vai além das práticas gramaticais transmissíveis e que aponta para estratégias inovadoras em busca de uma reflexão sobre o uso da 
língua. Pensar a inovação implica conceber o ensino de língua como um contínuo, um processo dinâmico em que currículo, conteúdo e aulas práticas estão em permanente transformação, mas nunca estáticos. Claro que essas transformações trazem em seu bojo aquilo que se afigura como novo, mas também a permanência de certos aspectos de uma tradição. Na seção a seguir, apresentamos a fundamentação metodológica deste trabalho.

\section{Bases e procedimentos para análise de dados}

Esta pesquisa respalda-se teórico-metodologicamente na Linguística Aplicada (LA) de caráter indisciplinar. A LA se formula enquanto área mediadora entre a teoria linguística e o ensino de línguas, cujo objetivo é reconhecer os tipos de conhecimentos que podem ser relevantes para a investigação dos processos de ensino, e os que precisam ir além daqueles formulados pela Linguística (MOITA LOPES, 2006).

Nesse sentido, nossa metodologia de pesquisa aponta para um trabalho de natureza qualitativa e documental; qualitativa porque descrevemos e analisamos o processo de construção do eixo AL a partir da comparação entre duas versões elaboradas da BNCC, e de caráter documental por nosso corpus de análise ser formado por documentos. Estes entendidos como documentos/monumentos produtos da sociedade que os produziram segundo as relações de forças que aí detinham o poder, artefatos culturais que revelam a complexidade e heterogeneidade em que estão inseridos, resultado de uma montagem, consciente ou inconsciente, da história, da época e da sociedade que o produziram, ou seja, documentos que materializam a intenções dos sujeitos que os construíram (cf. LE GOFF, 1997).

Assim, a análise desses documentos enquanto documento/monumento nos permite recuperá-los e usá-los cientificamente, decifrando-os enquanto objetos de estudo. Como procedimentos de análise, foram feitas repetidas e minuciosas leituras dos dados, observando como o eixo AL se configura nesses documentos e de que maneira ele se (re)configura nas versões investigadas da BNCC, com foco comparativo entre elas. Nosso intuito é analisar as principais continuidades no processo de construção desse eixo. 
Após exaustiva leitura do componente de Língua Portuguesa, na Área de Linguagens, das duas versões, analisamos especificamente duas seções de cada. Na $2^{a}$ versão, analisamos a seção destinada ao componente de "Língua Portuguesa" (BRASIL, 2016, p. 8798) e a seção “A Língua Portuguesa nos Anos Finais do Ensino Fundamental”, (BRASIL, 2016, p. 327-367), especificamente o eixo de Conhecimentos sobre a língua e sobre a norma. E na versão homologada, a seção destinada ao componente de "Língua Portuguesa" (BRASIL, 2017, p. 67-87) e a seção intitulada de "Língua Portuguesa no Ensino Fundamental - Anos Finais: práticas de linguagem, objetos de conhecimento e habilidades", (BRASIL, 2017, p. 136-191), especificamente o eixo de Análise Linguística/ Semiótica. Do ponto de vista de seu conteúdo explícito, percebemos algumas linhas de continuidades e singularidades entre os documentos investigados.

A fim de sistematizar esses dados, identificamos nos documentos 11 (onze) parâmetros comparativos de análise, a saber: Nomenclatura do eixo; Apresentação do eixo; Descrição do eixo; Organização do eixo; Relação do eixo com os campos de atuação; Relação do eixo AL com os demais eixos; Descrição do componente curricular de Língua Portuguesa; Concepção de linguagem; Descrição da relação do componente com os campos de atuação; Objetos de conhecimento; Habilidades.

Em uma análise prévia dos dados utilizando esses parâmetros, percebemos que em ambas as versões investigadas podemos traçar tanto linhas de continuidades significativas quanto linhas de singularidade. Assumimos de não haver relações rígidas e/ou binárias entre o que é continuidade e o que é singularidade, uma vez que essa relação é porosa, permeada por diferentes estratégias linguísticas de materialização explícita nos documentos. Assim, para fins didáticos, destacamos neste trabalho, na seção a seguir, as linhas de continuidade que o eixo AL apresenta entre as versões analisadas e como elas se materializam.

\section{Análise de dados: Linhas de continuidade do eixo análise linguística na BNCC}

Dentre os onze parâmetros comparativos identificados, percebemos linhas de continuidades entre a $2^{a}$ e $3^{a}$ versão da BNCC em seis deles, a saber: (i) Descrição do eixo AL; 
(ii) Relação do eixo com os campos de atuação; (iii) Relação do eixo AL com os demais eixos; (iv) Descrição da relação do componente com os campos de atuação; (v) Descrição do componente curricular de Língua Portuguesa e (vi) Concepção de linguagem. Nesses seis parâmetros/descritores comparativos, distinguimos que as linhas de continuidade podem ser agrupadas nas seguintes categorias: por continuidade textual, epistemológica, e filiação documental, como ilustra o quadro abaixo.

Quadro 1 - Linhas de continuidades entre a $2^{\mathrm{a}}$ e $3^{\mathrm{a}}$ versão da BNCC

\begin{tabular}{|l|c|c|c|}
\hline \multicolumn{1}{|c|}{ Parâmetros comparativos } & Textual & $\begin{array}{c}\text { Epistemo- } \\
\text { lógica }\end{array}$ & $\begin{array}{c}\text { Filiação do- } \\
\text { cumental }\end{array}$ \\
\hline Descrição do eixo AL & $\mathrm{X}$ & & \\
\hline Relação do eixo com os campos de atuação & $\mathrm{X}$ & & \\
\hline $\begin{array}{l}\text { Descrição da relação do componente LP com os cam- } \\
\text { pos de atuação }\end{array}$ & & $\mathrm{X}$ & $\mathrm{X}$ \\
\hline Relação do eixo AL com os demais eixos & & $\mathrm{X}$ & \\
\hline $\begin{array}{l}\text { Descrição do componente curricular de Língua Portu- } \\
\text { guesa }\end{array}$ & & & $\mathrm{X}$ \\
\hline Concepção de linguagem & & & \\
\hline
\end{tabular}

Fonte: Elaborado pela autora.

O quadro 1 ilustra como as linhas de continuidade podem ser agrupadas. A primeira coluna do quadro lista os parâmetros comparativos analisados, enquanto as outras três colunas compreendem as microcategorias de análise mapeadas nos processos de análise dos dados. Como indica o destaque na segunda coluna, há uma maior predominância de continuidade textual em dois parâmetros: (i) Descrição do eixo AL, (ii) Relação do eixo com os campos de atuação. Em relação à continuidade epistemológica, como indica a terceira coluna do quadro, pode-se observar uma maior predominância dessa linha nos parâmetros de (iii) Descrição da relação do componente LP com os campos de atuação, (iv) Relação do eixo AL com os demais eixos e de (v) Descrição do componente curricular de Língua Portuguesa. A quarta coluna do quadro, por sua vez, mostra que o parâmetro de (vi) Concepção de linguagem demonstra linhas de continuidade com a filiação documental. 
É importante destacar que essas linhas materializam-se basicamente através dos mecanismos linguísticos de reiteração e paráfrase, conforme demonstramos nas três subseções: continuidade textual, continuidade epistemológica e continuidade por filiação documental.

\section{Continuidade textual}

A continuidade textual identificada entre as diferentes versões da BNCC investigadas diz respeito ao aproveitamento de partes do texto da versão anterior na versão subsequente, para isso focalizar os procedimentos linguísticos usados na tessitura textual dos documentos se mostrou relevante. Isto nos parece evidência da relação processo e produto, pois, sinaliza que as versões subsequentes a primeira não eram necessariamente versões novas, diferentes das anteriores, no caso em pauta, especificamente entre a $2^{\mathrm{a}}$ e $3^{\mathrm{a}}$ versão essa relação se mostrou significativa.

Para compreender como as linhas de continuidade se materializam nos parâmetros/descritores comparativos investigados, organizamos paralelamente os excertos correspondentes a esses descritores presentes na $2^{\mathrm{a}}$ e $3^{\mathrm{a}}$ versão da BNCC. Esse movimento nos possibilitou observar que as linhas de continuidade desses documentos materializamse por meio dos procedimentos linguísticos da reiteração de itens lexicais e paráfrase.

De acordo com o Dicionário Houaiss (2008), o verbo "reiterar" significa dizer ou fazer de novo; repetir. Para Linguística Textual, o movimento de reiterar é um procedimento linguístico próprio da progressão textual, ou sequenciação, cuja função é “estabelecer entre os segmentos do texto (enunciados, parte de enunciados, parágrafos e mesmo sequências textuais) diversos tipos de relações semânticas e/ou pragmático-discursivas" (KOCH, 2002, p. 121).

Além da reiteração de itens lexicais, Koch (2002) destaca também a paráfrase, o paralelismo, a recorrência de elementos fonológicos, de tempos verbais, etc., como mecanismos de sequenciação próprios da língua que garantem a progressão de um texto. Segundo a autora, "a progressão textual pode realizar-se por meio de atividades formulativas em que o locutor opta por introduzir no texto recorrências de variados tipos" (KOCH, 
2002, p. 121), como as mencionadas acima. Na análise dos documentos investigados, percebemos que a tessitura textual destas versões apresenta recorrência dos mecanismos de reiteração de itens lexicais e paráfrase.

Ao analisarmos a Descrição do eixo Análise Linguística percebemos que há uma reiteração das proposições apresentadas na $2^{a}$ versão no texto da $3^{a}$ versão da BNCC. Vejamos o quadro abaixo, no qual o destaque, em fonte vermelha, ressalta a reiteração de trechos.

Quadro 2 - Descrição do eixo Análise Linguística

\begin{tabular}{|c|c|}
\hline $2^{a}$ versão da $\mathrm{BNCC}$ & $3^{\text {a }}$ versão da BNCC \\
\hline $\begin{array}{l}\text { Nos Anos Finais do Ensino Fundamental, os conhe- } \\
\text { cimentos sobre a língua e sobre a norma-padrão se } \\
\text { articulam aos demais eixos em que se organizam os } \\
\text { objetivos de aprendizagem e desenvolvimento de } \\
\text { Língua Portuguesa. As abordagens linguística, meta- } \\
\text { linguística e reflexiva, ocorrem, desta forma, sempre } \\
\text { a favor da prática de linguagem que está em evidência } \\
\text { nos eixos de leitura, escrita ou oralidade. } \\
\text { Os conhecimentos sobre a língua e a norma padrão } \\
\text { não devem ser tomados como uma lista de conteú- } \\
\text { dos dissociados das práticas de linguagem, mas como } \\
\text { propiciadores de reflexão a respeito do funciona- } \\
\text { mento da língua no contexto dessas práticas. A sele- } \\
\text { ção desses objetivos na BNCC, considera aqueles co- } \\
\text { nhecimentos fundamentais para que o/a estudante } \\
\text { possa apropriar-se do sistema linguístico que orga- } \\
\text { niza o Português Brasileiro. } \\
\text { Alguns desses objetivos, sobretudo aqueles que di- } \\
\text { zem respeito à norma, são transversais a toda a base } \\
\text { de Língua Portuguesa. O conhecimento da ortogra- } \\
\text { fia, da pontuação, da acentuação, por exemplo, deve } \\
\text { estar presente ao longo de toda escolaridade, aborda- } \\
\text { dos conforme o ano da escolaridade. Assume-se, na } \\
\text { BNCC de Língua Portuguesa, uma perspectiva de } \\
\text { progressão de conhecimentos que vai das regularida- } \\
\text { des às irregularidades e dos usos mais frequentes e } \\
\text { simples aos menos habituais e mais complexos. } \\
\text { (BRASIL, 2016, p. 329) }\end{array}$ & $\begin{array}{l}\text { Também, como já mencionado, nos Anos Finais do } \\
\text { Ensino Fundamental, os conhecimentos sobre a lín- } \\
\text { gua,_sobre as demais semioses e sobre a norma-pa- } \\
\text { drão se articulam aos demais eixos em que se organi- } \\
\text { zam os objetivos de aprendizagem e desenvolvi- } \\
\text { mento de Língua Portuguesa. Dessa forma, as abor- } \\
\text { dagens linguística, metalinguística e reflexiva ocor- } \\
\text { rem sempre a favor da prática de linguagem que está } \\
\text { em evidência nos eixos de leitura, escrita ou orali- } \\
\text { dade. } \\
\text { Os conhecimentos sobre a língua, as demais semio- } \\
\text { ses e a norma-padrão não devem ser tomados como } \\
\text { uma lista de conteúdos dissociados das práticas de } \\
\text { linguagem, mas como propiciadores de reflexão a } \\
\text { respeito do funcionamento da língua no contexto } \\
\text { dessas práticas. A seleção de habilidades na BNCC } \\
\text { está relacionada com aqueles conhecimentos funda- } \\
\text { mentais para que o estudante possa apropriar-se do } \\
\text { sistema linguístico que organiza o português brasi- } \\
\text { leiro. } \\
\text { Alguns desses objetivos, sobretudo aqueles que di- } \\
\text { zem respeito à norma, são transversais a toda a base } \\
\text { de Língua Portuguesa. O conhecimento da ortogra- } \\
\text { fia, da pontuação, da acentuação, por exemplo, deve } \\
\text { estar presente ao longo de toda escolaridade, aborda- } \\
\text { dos conforme o ano da escolaridade. Assume-se, na } \\
\text { BNCC de Língua Portuguesa, uma perspectiva de } \\
\text { progressão de conhecimentos que vai das regularida- } \\
\text { des às irregularidades e dos usos mais frequentes e } \\
\text { simples aos menos habituais e mais complexos. } \\
\text { (BRASIL, 2017b, p. 139) }\end{array}$ \\
\hline
\end{tabular}

Fonte: Elaborado pela autora 
O quadro 2, que está organizado em duas colunas correspondentes a descrição do eixo Análise Linguística na $2^{\mathrm{a}}$ e $3^{\mathrm{a}}$ versão, ilustra como este eixo é descrito de forma praticamente idêntica em ambas as versões, o destaque em azul ressalta a reiteração e os destaques em branco acentuam as novidades do texto na versão homologada.

À luz dos estudos sobre textualidade, “a reiteração ou repetição de itens lexicais tem por efeito trazer ao enunciado um acréscimo de sentido, que ele não teria se o item fosse usado somente uma vez" (KOCH, 2002, p. 121). No exemplo em destaque, temos um longo segmento textual que se repete de forma idêntica em dois documentos. Essa repetição, assim como ocorre para os itens lexicais dentro de um mesmo texto, nos parece apontar para intensificação/ênfase das proposições empregadas. Isto indica que a proposta de análise linguística se revela muito semelhante nas duas versões da BNCC.

Salvo as inserções relativas à semiose - o grande diferencial no texto homologado -, esse é um exemplo de linhas de continuidade significativas no âmbito epistemológico, posto que ambas as versões compreendem que o tratamento didático dos conhecimentos linguísticos deve se articular com os eixos leitura, produção textual e oralidade, de forma transversal e progressiva ao longo de toda a escolaridade. Desse modo, há reiteração de texto nas duas versões e ambas descrevem a relação do eixo AL com os demais eixos da mesma maneira, apesar de nomeá-los de forma diferente, como exploraremos mais adiante.

Tanto a $2^{\mathrm{a}}$ versão quanto a $3^{\mathrm{a}}$ compreendem a prática de análise linguística a partir das abordagens linguística, metalinguística e reflexiva da língua, cujo objetivo é propiciar que o estudante possa apropriar-se do sistema linguístico que organiza o português brasileiro. Essa concepção de ensino-aprendizagem no contexto escolar, apesar de não ser indicada explicitamente pelo documento tem como precursor Geraldi ([1984] 1997) e pertence ao paradigma inovador de ensino de Português, no qual, o objeto de ensino privilegiado é o texto ao qual ensino dos aspectos normativos estaria subordinado. Isto é, as regras gramaticais não seriam mais ensinadas por meio de frases soltas, fora de contexto, e sim na perspectiva de sua funcionalidade textual.

No que concerne o descritor Relação do eixo com os campos de atuação, observamos linhas de continuidade tanto no que diz respeito à composição do texto como no que 
diz respeito às ideias propostas, conforme demonstra o quadro abaixo. Essas linhas de continuidade se materializam através da reiteração textual, em destaque na cor vermelha, e paráfrase, em verde no quadro abaixo.

Quadro 3 - Relação com os campos de atuação

\begin{tabular}{|c|c|}
\hline $2^{\mathrm{a}}$ versão da BNCC & $3^{a}$ versão da BNCC \\
\hline $\begin{array}{l}\text { "[...] Compreende-se, então, que a divisão por cam- } \\
\text { pos de atuação tem, no componente Língua Portu- } \\
\text { guesa, uma função didática, pois, além de levar à } \\
\text { compreensão de que os textos circulam dinamica- } \\
\text { mente na prática escolar e na vida social, contribui } \\
\text { para a necessária organizacão dos saberes sobre a } \\
\text { língua, nos tempos e espaços da escola. São apresen- } \\
\text { tados, a seguir, os campos de atuação em que se or- } \\
\text { ganizam as práticas de leitura, escrita e oralidade da } \\
\text { Base Nacional Comum Curricular de Língua Portu- } \\
\text { guesa". (BRASIL, } 2016, \text { p. } 90 \text { ) }\end{array}$ & $\begin{array}{l}\text { "Compreende-se, então, que a divisão por campos } \\
\text { de atuacão tem também, no componente Língua } \\
\text { Portuguesa, uma função didática de possibilitar a } \\
\text { compreensão de que os textos circulam dinamica- } \\
\text { mente na prática escolar e na vida social, contribu- } \\
\text { indo para a necessária organizacão dos saberes so- } \\
\text { bre a língua e as outras linguagens, nos tempos e es- } \\
\text { paços escolares". (BRASIL, 2017b, p. } 85 \text { ) }\end{array}$ \\
\hline
\end{tabular}

Fonte: Elaborado pela autora

Como mostra o quadro 3, as duas versões da BNCC podem ser tomadas como versões de um mesmo documento. Inferimos isso pelo mecanismo de progressão textual usado para indicar a relação do eixo análise linguística com os campos de atuação. Se na reiteração de itens lexicais há recorrência/repetição de palavras e estruturas sintáticas, "tem-se, na paráfrase, um mesmo conteúdo semântico apresentado sob formas estruturais diferentes" (KOCH, 2002, p. 122). O uso desse mecanismo na tessitura do texto desses documentos produz um efeito de ênfase no conceito abordado, de tal modo que a mensagem se torne mais presente na memória do leitor.

Ao observamos como linguisticamente o texto é marcado pela reiteração, em destaque azul, e paráfrase, em destaque verde, constatamos que esse é um indício de linha de continuidade significativa nas duas versões. $\mathrm{Na} 3^{\mathrm{a}}$ versão, verificamos a estratégia de reiteração da $2^{\mathrm{a}}$ versão no que diz respeito à relação do eixo relativo aos conhecimentos sobre a língua com os campos de atuação. As duas versões da BNCC apresentam a mesma compreensão sobre a função dos campos de atuação no componente de Língua Portuguesa. Essa reiteração reforça um conceito inovador da BNCC presente em ambas as versões: os 
campos de atuação. Com isso, observamos que a continuidade textual não se separa da continuidade epistemológica, a ser apresentada a seguir.

\section{Continuidade Epistemológica}

A continuidade epistemológica diz respeito às ideias e/ou conceitos presentes nos dois documentos analisados. Os dados apontam para a presença de conhecimentos próprios dos Estudos Linguísticos, pertencentes ao paradigma inovador de ensino de Português, por isso o caráter de manutenção epistemológica. Essa linha de continuidade também materializa-se através dos mecanismos de reiteração e paráfrase textual.

$\mathrm{O}$ quadro a seguir mostra como a BNCC indica que os campos de atuação sejam abordados em sala de aula. Em destaque vermelho, pode-se observar a reiteração textual, em negrito, a reiteração de ideias e em verde, a paráfrase.

Quadro 4 - Descrição da relação do componente LP com os campos de atuação

\begin{tabular}{|c|c|}
\hline NCC & \\
\hline $\begin{array}{l}\text { Na BNCC, a organização das práticas de lingua- } \\
\text { gem (leitura, escrita, oralidade) por campos de } \\
\text { atuação aponta para a importância da contextu- } \\
\text { alização do conhecimento escolar, para a ideia } \\
\text { de que essas práticas derivam de situações da } \\
\text { vida social e, ao mesmo tempo, precisam ser si- } \\
\text { tuadas em contextos significativos para os/as } \\
\text { estudantes. A escolha de alguns campos específi- } \\
\text { cos, no conjunto maior de práticas de letramento, } \\
\text { deu-se por se entender que eles contemplam di- } \\
\text { mensões formativas importantes de uso da es- } \\
\text { crita na escola para a garantia dos direitos de } \\
\text { aprendizagem que fundamentam a BNCC, anuncia- } \\
\text { dos na Introdução deste documento: uma formação } \\
\text { para a atuação em atividades do dia-a-dia, no espaço } \\
\text { familiar, escolar, cultural; uma formação que con- } \\
\text { templa a produção do conhecimento e a pesquisa; } \\
\text { uma formação para o exercício da cidadania, que en- } \\
\text { volve, por exemplo, a condição de se inteirar dos fa- } \\
\text { tos do mundo e opinar sobre eles; uma formação } \\
\text { estética, na experiência de leitura e escrita do texto } \\
\text { literário. } \\
\text { As fronteiras entre os campos de atuação são tê- } \\
\text { nues, ou seja, reconhece-se que alguns gêneros lis- } \\
\text { tados em um determinado campo de atuação podem } \\
\text { também estar referenciados a outros, existindo trân- }\end{array}$ & $\begin{array}{l}\text { "[...] na BNCC, a organização das práticas de lin- } \\
\text { guagem (leitura de textos, produção de textos, ora- } \\
\text { lidade e análise linguística/semiótica) por campos } \\
\text { de atuação aponta para a importância da con- } \\
\text { textualização do conhecimento escolar, para a } \\
\text { ideia de que essas práticas derivam de situações } \\
\text { da vida social e, ao mesmo tempo, precisam ser } \\
\text { situadas em contextos significativos para os es- } \\
\text { tudantes. [...] } \\
\text { A escolha por esses campos, de um conjunto maior, } \\
\text { deu-se por se entender que eles contemplam di- } \\
\text { mensões formativas importantes de uso da lin- } \\
\text { guagem na escola e fora dela e criam condições } \\
\text { para uma formação para a atuação em atividades do } \\
\text { dia a dia, no espaço familiar e escolar, uma formação } \\
\text { que contempla a produção do conhecimento e a } \\
\text { pesquisa; o exercício da cidadania, que envolve, por } \\
\text { exemplo, a condição de se inteirar dos fatos do } \\
\text { mundo e opinar sobre eles, de poder propor pautas } \\
\text { de discussão e soluções de problemas, como forma } \\
\text { de vislumbrar formas de atuação na vida pública; } \\
\text { uma formação estética, vinculada à experiência de } \\
\text { leitura e escrita do texto literário e à compreensão e } \\
\text { produção de textos artísticos multissemióticos. [...]. } \\
\text { Os campos de atuação orientam a seleção de gêne- } \\
\text { ros, práticas, atividades e procedimentos em cada } \\
\text { um deles. Diferentes recortes são possíveis quando }\end{array}$ \\
\hline
\end{tabular}


oralidade do campo do cotidiano, por exemplo, podem muito bem levar ao exercício da cidadania ou à apreciação estética. [...]" (Brasil, 2016, p. 90) (Brasil, 2016, p. 90) se pensa em campos. As fronteiras entre eles são tênues, ou seja, reconhece-se que alguns gêneros incluídos em um determinado campo estão também referenciados a outros, existindo trânsito entre esses campos. [...]" (Brasil, 2017b, p. 84-85)

Fonte: Elaborado pela autora

Em relação ao descritor de Descrição da relação do componente LP com os campos de atuação, o quadro 4 ilustra como esse conceito é apresentado em ambas as versões da BNCC investigadas. Do ponto de vista epistemológico, isto é da continuidade de ideias, esse quadro demonstra a relação dos campos de atuação com as práticas de linguagem como dimensão formativa de uso da linguagem na escola, tanto no uso da escrita, como especifica a $2^{a}$ versão, como em outras modalidades da linguagem, como amplia a $3^{\text {a }}$ versão.

Campos de atuação podem ser entendidos como dimensões formativas de uso da linguagem na escola, como circunstâncias de contextualização do conhecimento escolar. Entretanto, não há uma definição stricto sensu para este conceito nos documentos, a BNCC apenas apresenta campos de atuação como relacionados às práticas de linguagem. Essa concepção de campos de atuação parece-nos filiar-se teoricamente à ideia de campos formulada por Pierre Bourdieu, em seu livro Os usos sociais da ciência: Por uma sociologia clínica do campo cientifico ([1997] 2004).

A noção de campo, para Bourdieu (2004), é usada para designar um espaço, microcosmos relativamente autônomo, dotado de suas próprias leis, ao mesmo tempo em que está submetido a leis sociais mais amplas, macrocosmo. Cada campo possui suas próprias demandas, faz imposições, solicitações, etc., relativamente independentes das pressões externas, que só se exercem e são mediatizadas pela própria lógica do campo (BOURDIEU, 2004).

Um indicativo da filiação da BNCC com a noção de campo de Bourdieu é a forma com que os campos de atuação são denominados, a saber: campo da vida cotidiana; campo artístico-literário; campo das práticas de estudo e pesquisa; campo jornalístico-midiático; e campo de atuação na vida pública. Os campos de atuação elencados pela BNCC do EF lembram a própria nomenclatura usada por Bourdieu: campo literário, artístico, jurídico ou científico. A ideia de que os campos de atuação derivam de situações da vida social e de 
que possuem fronteiras tênues entre si, reforçam a compreensão de que os textos circulam dinamicamente na prática escolar e na vida social.

No descritor Relação do eixo AL com os demais eixos de ensino, a análise de dados mostra que a continuidade se mostra em duas linhas. Uma delas é a do texto e a outra é a das ideias e concepções. No quadro abaixo a reiteração textual está destacada em vermelho e a reiteração de ideias em negrito para facilitar a análise.

Quadro 5 - Relação do eixo AL com os demais eixos de ensino

\begin{tabular}{|l|l|}
\hline \multicolumn{1}{|c|}{ 2 $^{\text {a versão da BNCC }}$} & \multicolumn{1}{c|}{$\mathbf{3}^{\text {a versão da BNCC }}$} \\
\hline "Se uma face do aprendizado da Língua Portu- & "Se uma face do aprendizado da Língua Portuguesa de- \\
guesa decorre da efetiva atuação do/a estudante & corre da efetiva atuação do estudante em práticas de \\
em práticas de linguagem de três tipos (orali- & linguagem que envolvem a leitura/escuta e a produ- \\
dade, leitura e escrita), situadas em campos de & ção de textos orais, escritos e multissemióticos, situa- \\
atuação específicos, a outra face provém da & das em campos de atuação específicos, a outra \\
reflexão sobre a própria experiência de reali- & face provém da reflexão/análise sobre/da própria \\
zação dessas práticas. Temos aí, portanto, o & experiência de realização dessas práticas. Temos \\
eixo do conhecimento sobre a língua e sobre a & aí, portanto, o eixo da análise linguística/semiótica, que \\
norma padrão, que se desenvolve transversal- & envolve o conhecimento sobre a língua, sobre a norma- \\
mente aos três eixos - leitura, escrita e oralidade & padrão e sobre as outras semioses, que se desenvolve \\
- e envolve análise textual, discursiva, gramatical & transversalmente aos dois eixos - leitura/escuta e \\
e lexical" (BRASIL, 2016, p. 95) & produção oral, escrita e multissemiótica - e que en- \\
volve análise textual, gramatical, lexical, fonológica \\
e das materialidades das outras semioses" (BRASIL, \\
2017b, p. 80)
\end{tabular}

Fonte: Elaborado pela autora

Como podemos observar no quadro 5 , há reiteração textual na $3^{\mathrm{a}}$ versão em relação à $2^{\mathrm{a}}$. Os destaques em azul indiciam como os dois textos podem ser tomados como versões preliminar e melhorada de uma mesma peça, visto que o texto da versão homologada é maior, do ponto de vista da mancha de texto na página, entretanto mantém grande parte do que havia sido dito na $2^{\mathrm{a}}$ versão. Do ponto de vista da continuidade de ideias, ou seja, do caráter epistemológico, esse quadro demonstra que as ideias de práticas de linguagem, campos de atuação e transversalidade do eixo se mantém em ambas as versões, embora dessincretizadas e não definidas.

A manutenção do caráter de transversal do eixo de AL em relação aos demais eixos de ensino elencados pela BNCC, além de significativa linha de continuidade, também aponta para o conceito teórico-metodológico de Análise Linguística proposto por Geraldi 
([1984]1997). Esse conceito vem sendo ampliado e aprofundado por diversos pesquisadores contemporâneos da área, como Mendonça (2006, p. 208), que compreende a análise linguística como "parte das práticas de letramento escolar, consistindo numa reflexão explícita e sistemática sobre a constituição e o funcionamento da linguagem nas dimensões sistêmica (ou gramatical), textual, discursiva e também normativa". Seu objetivo é "contribuir para o desenvolvimento de habilidades de leitura/escuta, de produção de textos orais e escritos e de análise e sistematização dos fenômenos linguísticos" (MENDONÇA, 2006, p. 208).

Quanto ao parâmetro Descrição do Componente Língua Portuguesa, os dados nos levam à construção do quadro a seguir. O destaque em vermelho realça a reiteração de itens lexicais, o verde, a paráfrase de ideias, e o destaque em ciano mostra uma distinção em relação aos verbos usados para descrever o objetivo da disciplina Língua Portuguesa.

Quadro 6 - Descrição do componente Língua Portuguesa

\begin{tabular}{|l|l|}
\hline \multicolumn{1}{|c|}{$\mathbf{2}^{\mathbf{a}}$ versão da BNCC } & \multicolumn{1}{c|}{$\mathbf{3}^{\mathbf{a}}$ versão da BNCC } \\
\hline "O ensino da Língua Portuguesa na Educação Bá- & "Ao componente Língua Portuguesa cabe, então, \\
sica deve proporcionar aos/às estudantes experiên- & proporcionar aos estudantes experiências que con- \\
cias que ampliem suas ações de linguagem, contri- & tribuam para a ampliação dos letramentos, de forma \\
buindo para o desenvolvimento do letramento, en- & a possibilitar a participação significativa e crítica nas \\
tendido como uma condição que permite ler e es- & diversas práticas sociais permeadas/constituídas \\
crever em diversas situações pessoais, sociais e es- & pela oralidade, pela escrita e por outras linguagens" \\
colares. [...]" (BRASIL, 2016, p. 87 ) & (BRASIL, 2017b, p. 67-68) \\
\hline
\end{tabular}

Fonte: Elaborado pela autora

Comparativamente a descritores anteriores, apresentados nesta análise, o quadro 6 destaca-se pela menor proporção de reiteração textual. Todavia, pode-se observar linhas de continuidade de caráter epistemológico quanto à descrição do componente Língua Portuguesa que se mostram na reiteração de partes do texto da $2^{\mathrm{a}}$ versão na $3^{\mathrm{a}}$ versão e na compreensão das finalidades do ensino e do componente de Língua Portuguesa.

Podemos apontar ainda uma diferença conceitual significativa entre ensino de e componente língua portuguesa. No primeiro caso, temos uma designação geral o segundo temos uma perspectiva mais curricular relativa à língua como um objeto de ensino. Porém, de acordo com os documentos, através de modalização deôntica (NASCIMENTO, 2010), a um e outro deve/cabe proporcionar aos estudantes experiências relativas à linguagem. 
No caso do documento da $2^{\mathrm{a}}$ versão, serão experiências que ampliarão ações de linguagem. No caso da $3^{a}$ versão, são experiências que contribuirão para a ampliação dos letramentos, há mais modalização do discurso.

Os documentos singularizam-se no que diz respeito ao entendimento do que é letramento - $2^{\mathrm{a}}$ versão - e quanto ao resultado da contribuição da ampliação das experiências com o letramento $-3^{a}$ versão. No primeiro caso, o foco parece ser o letramento como condição para agir dentro e fora da escola. No segundo caso, o foco é a "participação significativa e crítica nas diversas práticas sociais permeadas/constituídas pela oralidade." Diferença sutil, porém, significativa, pois, no primeiro caso, o letramento aparece a serviço da instrumentalização e no segundo aparece a serviço de uma atuação social crítica em prática sociais que envolvem a linguagem em suas várias semioses. A seguir, exploramos de que modo a continuidade por filiação documental ocorre nas versões da BNCC investigadas.

\section{Continuidade por filiação documental}

A continuidade por filiação documental diz respeito às linhas de continuidade com documentos curriculares anteriores. Pode-se observar isto no parâmetro de concepção de linguagem adotada pela BNCC, no qual ambas as versões investigadas indicam manutenção de vínculo com documentos curriculares precedentes, como podemos observar no quadro abaixo. O destaque em vermelho realça a citação aos PCNs através da reiteração textual e o destaque em verde, a paráfrase ao mencionar documentos curriculares anteriores.

Quadro 7 - Concepção de linguagem

\begin{tabular}{|l|l|}
\hline \multicolumn{1}{|c|}{$\mathbf{2}^{\mathbf{a}}$ versão da BNCC } & \multicolumn{1}{|c|}{$\mathbf{3}^{\mathbf{a}}$ versão da BNCC } \\
\hline "A base comum para os currículos de Língua Por- & "O componente Língua Portuguesa da BNCC dia- \\
tuguesa, aqui apresentada, dialoga com a perspectiva & loga com documentos e orientações curriculares \\
discursiva da linguagem, já apontada em outros do- & produzidos nas últimas décadas, buscando atualizá- \\
cumentos, como os Parâmetros Curriculares Nacio- & los em relação às pesquisas recentes da área e às \\
nais (PCNs), para os quais "a linguagem é uma & transformações das práticas de linguagem ocorridas \\
forma de ação interindividual orientada para uma fi- & neste século, devidas em grande parte ao desenvol- \\
nalidade específica; um processo de interlocução & vimento das tecnologias digitais da informação e co- \\
que se realiza nas práticas sociais existentes numa & municação (TDIC) \\
sociedade, nos distintos momentos de sua história". & $\begin{array}{l}\text { Assume-se aqui a perspectiva enunciativo-discursiva } \\
\text { de linguagem, já assumida em outros documentos, }\end{array}$ \\
\hline
\end{tabular}


Os enunciados ou textos são produzidos em uma situação de enunciação, determinada por condições históricas e sociais, por meio de discursos que instauram relações de poder. O aprendizado da leitura, da escrita e da oralidade culta envolve a compreensão dessas situações. [...]"

A Base Nacional Comum Curricular, na sua qualidade de referência para a elaboração de propostas curriculares, apresenta um diálogo estreito com concepções já possivelmente disseminadas em contextos de formação de professores/as e conhecidas no ambiente escolar. Conceitos como discurso e gêneros textuais/discursivos, por exemplo, que fundamentam a organização deste documento, vêm sendo discutidos e aprofundados, pelos estudos linguísticos e também pela apropriação desses estudos no campo educacional, ao longo das últimas décadas. Em continuidade ao que foi proposto pelos PCNs, o texto ganha centralidade na organização dos objetivos de aprendizagem e desenvolvimento do componente Língua Portuguesa (Brasil, 2016, p. 88-89) como os Parâmetros Curriculares Nacionais (PCN), para os quais a linguagem é "uma forma de ação interindividual orientada para uma finalidade específica; um processo de interlocução que se realiza nas práticas sociais existentes numa sociedade, nos distintos momentos de sua história" (Brasil, 1998, p. 20)

Tal proposta assume a centralidade do texto como unidade de trabalho e as perspectivas enunciativodiscursivas na abordagem, de forma a sempre relacionar os textos a seus contextos de produção e o desenvolvimento de habilidades ao uso significativo da linguagem em atividades de leitura, escuta e produção de textos em várias mídias e semioses

Ao mesmo tempo que se fundamenta em concepções e conceitos já disseminados em outros documentos e orientações curriculares e em contextos variados de formação de professores, já relativamente conhecidos no ambiente escolar - tais como práticas de linguagem, discurso e gêneros discursivos/gêneros textuais, esferas/campos de circulação dos discursos -, considera as práticas contemporâneas de linguagem, sem o que a participação nas esferas da vida pública, do trabalho e pessoal pode se dar de forma desigual. Na esteira do que foi proposto nos Parâmetros Curriculares Nacionais, o texto ganha centralidade na definição dos conteúdos, habilidades e objetivos, considerado a partir de seu pertencimento a um gênero discursivo que circula em diferentes esferas/campos sociais de atividade/comunicação/uso da linguagem. [...]." (Brasil, 2017b, p. 67)

Fonte: Elaborado pela autora

Como pode ser observado, o quadro 7 mostra linhas de continuidade no "diálogo" de cada uma das versões da BNCC com os Parâmetros Curriculares Nacionais. Cabe destacar que esse diálogo, linguisticamente marcado, em ambas as versões, como o mesmo verbo - dialogar - tem escopos diferentes. $\mathrm{Na} 2^{\mathrm{a}}$ versão, o escopo citado é a Base Comum para os Currículos de Língua Portuguesa, ou seja, a ideia de um documento amplo. Já na $3^{a}$ versão, o escopo é o componente Língua Portuguesa dentro da BNCC.

Ainda dentro do que vem sendo apresentado, o descritor exposto no quadro acima apresenta uma linha de continuidade reiterativa no que diz respeito aos contextos em que as concepções assumidas por uma e outra versão, fundamentadas nos PCNs, se dá. Ambas 
as versões assumem "concepções e conceitos" relativas a discurso e gêneros textuais/discursivos já conhecidos em "contextos de formação de professores" e o "ambiente escolar". Cabe ainda destacar dentro da linha de continuidade textual a paráfrase, evidenciado em verde. Veja que este tipo de continuidade se mostra em ambos documentos, em ambas as colunas nos itens relativos ao diálogo com os PCNs. No texto da $2^{\mathrm{a}}$ versão, “outros documentos" é uma designação genérica para propostas curriculares anteriores, das quais destacam-se os PCNs. Pode-se observar essa relação direta quando a $2^{\mathrm{a}}$ versão defende a "articulação recursiva entre 'uso e reflexão', uma formulação teórica cara aos debates sobre ensino e aprendizagem de Língua Portuguesa, presente desde a década de 80 do século passado" (BRASIL, 2016, p. 95).

$\mathrm{Na}$ versão homologada, por sua vez, esse mesmo diálogo é indicado igualmente com outros documentos, mas também com orientações curriculares, ou seja, passa-se a definir que outros documentos são esses e dentro dos muitos que podem influenciar a atuação escolar destacam-se os curriculares e produzidos na última década.

Pode se observar também nesse quadro linhas de continuidade relativas à epistemologia. Nesse caso, temos o conceito de linguagem como interação que em ambas as versões é o mesmo dos PCNs, tendo sido citado inclusive entre aspas. Nesse caso, temos a superposição de duas linhas de continuidade. A epistêmica já apresentada em outros quadros e a que neste trabalho chamamos de "hereditária", ou seja, uma linha de continuidade que faz explícita menção aos documentos anteriores, inclusive citando-os. Essa linha se mostra importante para a arquitetura conceitual dos documentos analisados não apenas porque os interconecta, mas porque mostra que a BNCC surge também como filiação ao que já foi proposto para o componente de Língua Portuguesa em documentos anteriores.

No âmbito da linha de continuidade epistemológica, o texto indicado como unidade de trabalho é um conceito central a ambas as versões, isto está explícito na $2^{a}$ versão quando afirma que o "texto ganha centralidade na organização de objetivos de aprendizagem..." e, na $3^{\text {a }}$ versão, quando afirma que "tal proposta assume a centralidade do texto como unidade de trabalho...”. Na $2^{a}$ versão, esse termo aparece ainda como sinônimo de enunciado. 
Apesar dessas linhas de continuidade, chamamos a atenção para o fato de que o escopo do diálogo estabelecido com documentos anteriores muda nas versões analisadas. $\mathrm{Na} 2^{\mathrm{a}}$ versão da Base, o diálogo estabelecido com esses documentos é na perspectiva discursiva da linguagem, já na $3^{a}$ versão, o diálogo estabelecido assume a perspectiva enunciativo-discursiva da linguagem. Essas duas concepções situam-se historiograficamente no paradigma da virada linguística e no da inovação no ensino de língua, apesar de stricto sensu não serem iguais. Como se pode observar, no quadro em análise, as linhas continuidade textual com reiteração e paráfrase aparecem, mas não chegam a compor a maior parte do texto. Aparecem, então, linhas de continuidade epistemológica.

Em síntese, mapeadas as principais (des)continuidades sofridas pelo do eixo Análise Linguística, através de 11 (onze) parâmetros comparativos entre as duas versões da BNCC, percebemos que ambas as versões possuem continuidades significativas entre si e documentos parametrizadores de ensino anteriores. A análise de dados demonstra que na parte textual do documento, as continuidades entre as versões da BNCC investigadas situam-se em continuidade textual, epistemológica e por filiação documental.

\section{Considerações finais}

Dado o objetivo de investigar como o eixo Análise Linguística foi (re)construído nas diferentes versões da BNCC do EF, com destaque para as linhas de continuidade que podem ser traçadas na $2^{\mathrm{a}}$ (BRASIL, 2016) e $3^{\mathrm{a}}$ versão (BRASIL, 2017), identificamos e mapeamos 11 (onze) parâmetros comparativos entre as duas versões da BNCC investigadas. A partir desses, percebemos seis deles apresentam linhas de continuidades textual e conceitual.

A análise de dados demonstra que na parte textual do documento, as linhas de continuidade entre as versões da BNCC estudadas situam-se em continuidade textual demonstrada através por mecanismos de reiteração e paráfrase; continuidade epistemológica identificada na manutenção das ideias e conceitos reiterados ou parafrasticamente apresentados; e por filiação documental manifesta na citação de documentos curriculares anteriores. 
As linhas de continuidade traçadas entre essas versões, em relação ao eixo Análise Linguística, mostram como os dois textos podem ser tomados como versões preliminar e melhorada de uma mesma peça, pela repetição de partes do texto e também pelo fato de que o texto da versão homologada é bem maior, seiscentas páginas ao todo. Os dados mostram que há uma interconexão tanto em relação à arquitetura estrutural quanto em relação a arquitetura conceitual dos documentos analisados, como indicado nas categorias de continuidade textual e epistemológica. Assim como também há uma filiação da BNCC com o que já foi proposto para o componente de Língua Portuguesa em documentos anteriores, como os PCN, especialmente em relação proposta de prática de Análise Linguística preconizada por Geraldi ([1984]1997) e diversos pesquisadores contemporâneos da área.

A análise de dados revela como significativo que a maior ocorrência de linhas de continuidade se dê na que nomeamos de continuidade epistemológica. Esse achado se mostra muito relevante em termos de proposição curricular no Brasil, ainda que a Base não pretenda ser vista como tal, pois indica que documentos como esses não surgem da mente criativa de alguns pesquisadores, mas resulta de estudos consolidados na área, de ideias aceitas pela comunidade científica. Esse achado ganha ainda mais importância se lembramos o contexto político no qual as versões foram escritas. Isso significa dizer que as equipes redatoras de cada uma das versões tinham uma linha de pensamento comum com muitas aproximações. A recorrência dos mecanismos de reiteração e de paráfrase reforçam a relação entre processo e produto, pois, assim como cada versão pode ser vista como o produto de uma etapa ela também pode ser vista como parte de um processo extenso de negociação com atores implicados (secretarias de educação, professores, Conselho Nacional de Educação, sociedade) e de reivindicação desses mesmos atores.

Além dessas linhas de continuidade, é importante indicar que as versões da BNCC também apontam para singularidades, a exemplo da entrada do conceito de Semiótica na versão homologada. Estas serão objeto de um outro artigo, em andamento. 


\title{
THE LINGUISTIC ANALYSIS AXIS IN THE NCCB: AN ANALYSIS OF THE CONTINUITY LINES BETWEEN DIFFERENT VERSIONS OF THE BASE
}

\begin{abstract}
This study investigates how the Linguistic Analysis (LA) axis was (re) built on the National Common Curricular Base (BNCC) of Elementary Education. More specifically, it highlights the lines of continuity that this axis presents between the second version (BRASIL, 2016) and the third approved version (BRASIL, 2017) This research has theoretical and methodological support in Applied Linguistics, of a qualitative and documentary nature, with an interpretive focus on the AL axis of the Portuguese Language component. Among theoretical support, we can highlight some studies, such as Bezerra and Reinaldo (2013), Franchi ([1987] 2006), Geraldi ([1984] 1997), Mendonça (2006) on the practice of Linguistic Analysis in the school context. The analyzed data showed that in the discursive part of the document, the lines of continuity between the versions of the BNCC investigated are shown in textual continuity - manifested by mechanisms of reiteration and paraphrase -, epistemological - manifested in the maintenance of ideas and concepts - and by documentary affiliation - manifested in the link to previous curricular documents.
\end{abstract}

KEYWORDS: Linguistic Analysis; NCCB; Elementary School; Applied Linguistics;Portuguese language.

\section{REFERÊNCIAS}

APARÍCIO, Ana Sílvia Moço. A produção da inovação em aulas de gramática do ensino fundamental II da escola pública estadual paulista. 2006. 217 f. Tese (Doutorado em Linguística Aplicada) Instituto de Estudos da Linguagem. Universidade Estadual de Campinas, Campinas, SP.

BEZERRA, Maria Auxiliadora; REINALDO, Maria Augusta. Análise linguística, afinal, a que se refere? São Paulo: Cortez, 2013.

BRASIL. Ministério da Educação e Cultura. Base Nacional Comum Curricular: Educação é a base. (2 versão) Brasília: MEC, 2016. Disponível em <http://basenacionalcomum.mec.gov.br/historico> Acesso em 23 de nov. de 2019.

. Base Nacional Comum Curricular: Educação é a base. Brasília: MEC, 2017.

BOURDIEU, Pierre. Os usos sociais da ciência: por uma sociologia clínica do campo científico. São Paulo: UNESP, 2004. 86 p.

FRANCHI, Carlos; NEGRÃO, Esmeralda Vailati; MULLER, Ana Lúcia. Mas o que é mesmo "gramática"? São Paulo: Parábola Editorial, [1987] 2006.

GERALDI, José Wanderley. O texto em sala de aula. São Paulo: Editora Ática, [1984] 1997.

HOUAISS, Antônio; VILLAR, Mauro de Salles. Minidicionário Honaiss da língua portuguesa. 3 ed. rev. e aum. Rio de Janeiro: Objetiva, 2008.

LE GOFF, Jacques. Documento/monumento. In: Enciclopédia Einaudi: v. 1. memória-história. Lisboa: Imprensa Nacional - Casa da Moeda, 1997. p. 95-106. 
LINO DE ARAÚJO, Denise. CARVALHO, Aluska SIlva. FERREIRA, Elisa Cristina Amorim. Lingua e literatura no Ensino Médio: propostas. Campina Grande - PB: EDUFCG, 2017.

MENDONÇA, Márcia. Análise linguística no ensino médio: um novo olhar, um outro objeto. In: MENDONÇA, Márcia; BUNZEN, Clécio. Português no ensino médio e formação do professor. São Paulo: Parábola Editorial, 2006. p. 199-226

MOITA LOPES, Luiz Paulo da. Uma linguística aplicada mestiça e ideológica: interrogando o campo como linguista aplicado. In: MOITA LOPES, Luiz Paulo da. Por uma linguistica aplicada indisciplinar. São Paulo: Parábola, 2006. p. 13-44

NASCIMENTO, Erivaldo Pereira do. A modalização deôntica e suas peculiaridades semântico-discursivas. Fórum Linguistico, v. 7, n. 1, p. 30-45, 2010.

TEIXEIRA, Adriana. LITRON, Fernanda Félix. O manguebeat nas aulas de Português: Videoclipe e movimento cultural em rede. In: ROJO, Roxane Helena; R. MOURA, Eduardo (Orgs). Multiletramentos na escola. São Paulo: Parábola Editorial, 2012. p. 167-198.

Recebido em: 30/04/2020.

Aprovado em: 20/05/2020. 